\title{
Evaluation of antioxidant, antimicrobial and cytotoxic potential in Artemisia vulgaris L.
}

\author{
Asad Hamad ${ }^{1}$, Muhammad Arfan ${ }^{2}$, Shujaat Ali Khan ${ }^{1}$, Nighat Fatima ${ }^{1}$, Arshad \\ Mehmood Abbasi ${ }^{3 *}$, Abdul Mannan ${ }^{1 *}$ \\ 1. Department of Pharmacy, COMSATS University Islamabad (Abbottabad Campus-22060), Pakistan \\ 2. Department of Chemistry, School of Natural Sciences, National University of Science and \\ Technology, Islamabad 46000, Pakistan \\ 3. Department of Environmental Sciences, COMSATS University Islamabad (Abbottabad \\ Campus-22060), Pakistan
}

\begin{abstract}
Artemisia vulgaris L. (Mugwort or Afsantin) has been used to treat various diseases since ancient times by the inhabitants of Himalayan region-Pakistan. Methanolic fractions (HA1-HA9) obtained from the aerial parts of A. vulgaris were evaluated for their antioxidant, antimicrobial and brine shrimp cytotoxic activities. Fraction HA8 showed substantial phenolics content with value of $26.29 \pm 1.4 \mu \mathrm{gEQ} / \mathrm{mg}$ and DPPH scavenging (82.84 $3.01 \%$ ). Conversely, total flavonoids content of $7.32 \pm 0.07 \mu \mathrm{gEQ} / \mathrm{mg}$ was determined in HA1 fraction. Fraction HA1 also showed significant cytotoxic effect with the value LD50 of $144.94 \mu \mathrm{g} / \mathrm{mL}$. Fractions HA7 and HA9 depicted max-

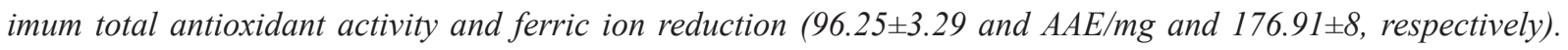
All fractions showed encouraging results against bacterial strains Bordetella bronchiseptica and Micrococcus luteus, while HA2 fraction showed the highest percentage inhibition Mucor species with zone of inhibition of $13.25 \pm 0.35 \mathrm{~mm}$. A total of 7 fractions showed significant antileishmanial activity with survival percentage ranging 0.00 to 19. To sum up, results of the current study indicated that the plant can be further explored for isolation of antileishmanial and antimicrobial compounds, which could be used for drug development.
\end{abstract}

Keywords:antioxidant, antimicrobial, antileishmanial, cytotoxicity, Artemisia vulgaris

Received: $4^{\text {th }}$ April 2018; Accepted: $4^{\text {th }}$ May 2018; Published: $22^{\text {nd }}$ July 2018

\section{Introduction}

More than $90 \%$ of therapeutic classes derived from natural prototypic products and twothirds of the total population relies upon herbals for basic pharmaceutical care [1]. Presence of bioactive compounds in plants is naturally gifted, since isolation of secondary metabolites from medicinal plants has led to breakthroughs in the form of new drug discovery [2-3]. Aspirin is a

*Corresponding authors: Arshad Mehmood Abbasi, COMSATS University Islamabad (Abbottabad Campus-22060), Pakistan. E-mail: arshad799@yahoo.com and Abdul Mannan, COMSATS University Islamabad (Abbottabad Campus-22060), Pakistan. E-mail: amannan@ciit.net.pk 
classic example of drug discovery, which was initially discovered as salicylic acid from willow bark and leaves. Likewise, taxol from the bark of yew trees has effectiveness against breast and ovarian cancers [2]. Systematic screening of microorganism, plants and animals is very fruitful in the discovery of novel antimicrobials [4]. Natural herbs possess a number of medicinal properties and are an excellent source of pharmaceutical and health care products [5]. It is well established that plant species have a cluster of antimicrobials. Therefore, screening of plant extracts was carried out to find new anti-infective agents [6-7]. The majority of the population in developing countries depends on natural resources, particularly medicinal plant species to treat infectious diseases [8-9]. Therefore, natural products have a leading role in the discovery of novel antibiotics [10]. For instance, most of the problems are associated with antibiotics, therefore significant research work has been focused on plant species which present remarkable antimicrobial effects [11-12].

Reactive oxygen species (ROS) have a major role in a number of pathological conditions. It is well accepted that in tissue injury a large amount of ROS is produced, which rapidly reacts with a number of biological macromolecules and causes oxidative alterations [13]. Free and oxidative radicals are the damaging entities because they affect proteins, membranes, lipids and nucleic acids and cause pulmonary diseases, inflammation, ischemia, cancer, diabetes and a number of degenerative disorders [14-24]. Plant based diets are suggested for patients suffering from cancer, cardiac dysfunctions, atherosclerosis, diabetes, hypertension and neurodegenerative disorders, because such diets are rich in secondary metabolites, which have anti-oxidative effects [21].

Phytochemicals are bioactive compounds, which are obtained from plants and contribute significantly to scavenge free radical species. Polyphenolic compounds with monocyclic aro- matic ring and aldehydic, alcoholic or carboxylic group [22] are present in almost every plant [23]. These compounds are involved in the shaping of plants, affect reproduction, growth and resistance to parasites and environment [21]. In addition, phenolic compounds present in foods, medicinal plants and beverages have shown significant antioxidant properties and free radical scavenging [24-25]. Like phenolics, flavonoids are color pigments, involved in pollination by appealing to animals with charming colors and prevent plant species from UV damage. Flavonoids possess numerous pharmacological activities such as: antitumor, anti-inflammatory, analgesic, anti-HIV, anti-infective, antioxidant, anti-hepatotoxic, immune-stimulant, vasodilator and antiulcerogenic activities. Hesperidin and rutin are biologically active flavonoids and have the capacity to minimize capillary fragility. Likewise, quercetin is important for its antidiarrheal activity [22]. Screening of phytochemical characters is done by crude fractions of plant extracts [26], whereas antioxidant activity is determined by redox reactions [27-28] using various assays. Among these, 2, 2 diphenyl 1 picrylhydrazyl (DPPH) assay, which was introduced by Marsden Blois, working at Stanford University nearly 56 years ago [22] is very popular for determining the antioxidant properties of plant extracts. Likewise, Phosphomolybdenum complex assay is commonly used to determine total antioxidant capacity [29].

The number of resistant microbial strains is increasing every day due to the excessive and unfair use of drugs. Food spoilage by fungi causes considerable economic loss and constitutes a health risk for consumers due to mycotoxins [28]. Regardless of the survival of strong antifungal agents, multi resistant strains are incessantly emerging [30]. Mucorales (zygomycete fungi) are primary causes of food spoilage of soy cakes, used in traditional foods in Asia [31]. The higher occurrence of Aspergillus niger in tem- 
perate and moist places is due to its capacity to survive over extensive $\mathrm{pH}$ range of 1.4-9.8 [32]. Aspergillus fumigatus produces countless conidia, which is released into the atmosphere and ultimately reaches alveoli in the lungs and causes serious health effects [33].

Brine shrimp 'Artemia salina' is an invertebrate, which is marine in habitat and its larva (Nauplii) can be grown in saline solution. Potential toxicity of plant extracts and presence of anti-cancer agents can be tested in tubes containing a known number of brine shrimps. In this assay live brine shrimps are counted after 6 and $24 \mathrm{~h}$ of the treatment and $\mathrm{LD}_{50}$ value is calculated, which corresponds to $50 \%$ death [22]. Leishmaniasis disease is mainly caused by protozoa of the genus Leishmania. This disease appears at cutaneous and/or visceral levels and is common in hot and humid regions [34]. Even though antileishmanial drugs are accessible, first-line chemotherapy is still based on pentavalent antimonials, which are toxic and prone to drug resistance. Moreover, substituted drugs i.e. amphotericin $\mathrm{B}$ and pentamidine have also many side-effects. In this context, use of miltefosine as a first oral treatment of visceral leishmaniasis was a major step forward. However, new, safe and cast effective preparations are still desirable [35-36]. Pharmacological activity of crude extracts can be measured and standardized with the help of biological assays. Scientifically, economically and ethically in-vitro assays are better to perform prior to in vivo. Bioactive components are preceded for clinical trials and adverse effects studies following in-vivo assays [22]. Bioassays have a fundamental role in drug discovery and in finding new therapeutic entities for the treatment of diseases [37]. In this context the present study was mainly focused on in vitro bioassays as they are quick and reproducible [38].

Artemisia vulgaris (L.) belongs to Asteraeceae family, commonly known as Mugwort and Afsantin. It is widespread in Himalayas region of Pakistan and traditionally used as an antiseptic, diuretic, analgesic, antipyretic, diaphoretic, anthelmintic, hypoglycemic, antispasmodic, larvicide, expectorant and tonic. This species is also an effective remedy to treat colic, depression, asthma, rheumatism cancer, dyspepsia, hepatosis, epilepsy, cough, diarrhea, headache, hemorrhage and inflammation [39]. Additionally, anti-nociceptive [40] and hepato-protective [41] properties have been reported in this plant species. A. vulgarisis is a well known medicinal plant species, which is traditionally used by the inhabitants of Himalayan region-Pakistan to treat various health disorders. However, its composition and properties have rarely been explored. Therefore, the present study was aimed to evaluate phenolics content, in vitro antioxidant, antimicrobial, antileishmanial and cytotoxic potential of $A$. vulgaris.

\section{Materials and Methods}

\section{Sampling and extraction}

Artemisia vulgaris was collected from Galyat Region of Abbottabad, Khyber Pakhtunkhwa, Pakistan and identified and voucher numbered 'PAC1007' by Dr. Muhammad Zafar, Plant Sciences Department, Quaid-i-Azam University, Islamabad-Pakistan. Afterwards plant specimen was submitted in the same herbarium. The aerial parts of plant were shade dried at room temperature and crushed into fine powder. The $2 \mathrm{~kg}$ powder was macerated in methanol for 10 days and then filtered. Finally, filtrate was evaporated under reduced pressure to obtain a thick semisolid paste.

\section{Fractionation}

Fractionation was carried out by column chromatography. Column was packed with slurry of silica gel (Merck Cat No.1.07734.1000) prepared in chloroform and $120 \mathrm{~g}$ dried extract was loaded on the top. The solvent was passed 
through the column in increasing order of polarity as $3 \%, 6 \%, 10 \%, 15 \%, 20 \%$ and finally $25 \%$ of $\mathrm{MeOH} / \mathrm{CHCl}_{3}$. The behavior of different fractions was observed on TLC plates, developed in $5 \% \mathrm{MeOH} / \mathrm{CHCl}_{3}$ and 9 fractions were obtained as HA1, HA2, HA3, HA4, HA5, HA6, HA7, HA8 and HA9.

\section{Determination of total phenolics and fla- vonoids}

Total phenolics content (TPC) in different fractions of $A$. vulgaris (HA1-HA9) fractions was determined using the method as described earlier [42]. In brief, $20 \mu 1$ of each crude fraction was taken in a test tube, followed by the addition of $90 \mu$ Lof the Folin-ciocalteu reagent. Samples were incubated for $5 \mathrm{~min}$ at room temperature, followed by the addition of $6 \%$ sodium carbonate $(90 \mu \mathrm{L})$. The reaction mixture was again incubated for $1 \mathrm{hr}$ at room temperature before taking absorbance at $715 \mathrm{~nm}$ using Gallic acid as standard. TPC was expressed as microgram Gallic acid equivalent per milligram ( $\boldsymbol{\mu g}$ GAE/mg). Data were presented as \pm of replicate analysis.

Total flavonoids content (TFC) was determined as explained before [43]. In short, $20 \mu \mathrm{L}$ of each fraction was added in a separate well of 96 wells plate and $10 \mu \mathrm{L}$ of potassium acetate was added in each well, followed by addition of $10 \mu \mathrm{L}$ of $10 \%$ aluminum chloride. Afterwards, $160 \mu \mathrm{L}$ of distilled water was supplemented to reconstitute volume up to $200 \mu \mathrm{L}$. The mixture was incubated for half an hour at room temperature. The absorbance of the reaction mixture was taken at $415 \mathrm{~nm}$ using quercetin as standard. TFC value was expressed as microgram quercetin equivalent per milligram ( $\mu \mathrm{g} \mathrm{QE} / \mathrm{mg}$ ).

\section{Antioxidant assays}

The antioxidant potential in different fractions of A. vulgaris was evaluated using different assays. DPPH free radical scavenging assay was performed using as reported previously
[44]. Briefly, $20 \mu$ Lcrude fraction was taken in 96 wells plate, followed by addition of $180 \mu \mathrm{LDPPH}$ reagent. This mixture was incubated at $37^{\circ} \mathrm{C}$ for 1 hour. Ascorbic acid was used as a positive control, whereas methanol was negative control. Final reading was taken using micro plate reader at $517 \mathrm{~nm}$. DPPH activity was intended by formula

(Percentage scavenging $=\left(\right.$ Abs. ${ }_{\text {control }}-$ Abs. sample $/$ Abs. $\left.{ }_{\text {control }}\right) \times 100$ )

Total antioxidant capacity was measured by phosphomolybdenum method [45]. Initially, $1.63 \mathrm{~mL}$ of $0.6 \mathrm{M}$ sulfuric acid, $1.68 \mathrm{~g} \mathrm{NaH}_{2} \mathrm{SO}_{4}$, $0.247 \mathrm{~g}$ of ammonium-molybdate was mixed, followed by addition of $50 \mathrm{mLdistilled} \mathrm{water.} \mathrm{Af-}$ terwards, $1 \mathrm{~mL}$ of this reagent was taken in eppendorf tubeand $0.1 \mathrm{mLof}$ the sample was mixed, followed by incubation at $95^{\circ} \mathrm{C}$ for $90 \mathrm{~min}$. After cooling, the absorbance of the reaction mixture was measured at $695 \mathrm{~nm}$ using a microplate reader. Total antioxidant capacity was measured as equivalent of ascorbic acid.

Ferric ion reducing power was estimated using protocol as describe previously [45]. The $0.2 \mathrm{M}$ phosphate buffer, $1 \%$ potassium ferricyanide, $10 \%$ trichloroacetic acid and $0.1 \%$ ferric chloride were used as stock solution. Briefly, $200 \mu \mathrm{L}$ of each fraction was taken in eppendorf tube and $500 \mu \mathrm{L}$ of each solution: potassium ferricyanide and buffer were mixed. After incubation at $50^{\circ} \mathrm{C}$ for $20 \mathrm{~min}, 500 \mu \mathrm{L}$ of trichloroacetic acid was mixed and centrifuged at 3000rpm for 10 min. Then $100 \mu \mathrm{L}$ of supernatant was poured in respective well of 96 well plate and $0.1 \%$ of ferric chloride was added along with $20 \mu \mathrm{L}$ of distilled water in each well. The readings were taken at $630 \mathrm{~nm}$ on micro plate reader.

\section{Antimicrobial assays}

Disc diffusion method was used to determine antibacterial activity as reported previously by using one gram positive and two gram negative strains [46]. Antibacterial activity of HA1-HA9 fractions was checked against $M i$ - 
crococcus luteus (M. luteus) (ATCC 10240), Bordetella bronchiseptica (B. bronchiseptica) (ATCC 4617), Salmonella typhimurium (S. typhimurium) (ATCC 14028) bacterial strains using cefotaxime and DMSO as positive and negative controls, respectively. The test concentration of each fraction used was $20 \mathrm{mg} / \mathrm{mL}$. The inoculums of each bacterium were swabbed smoothly on the surface of the sterilized nutrient agar media present in each plate and $5 \mu \mathrm{L}$ of each fraction was loaded on autoclaved filter paper discs, placed on respective places in the petri plates, which were incubated at $37^{\circ} \mathrm{C}$ for about $24 \mathrm{hrs}$ prior to measure the zone of inhibition. Each plate comprised two discs of positive and one disc of negative control.

The antifungal activity was evaluated using disc diffusion method as described previously [47] using Terbinafine and DMSO as positive and negative controls, respectively. Three fungal strains: Mucor species, Aspergillus fumigatus (A. fumigatus) and Aspergillus niger (A. niger) were used. Test concentration of each fraction was prepared as $20 \mathrm{mg} / \mathrm{mL}$. Assay was performed on solidified sterilized sabouraud dextrose agar (SDA) present in petriplate and different fungal solutions were swabbed on its surface. $5 \mu \mathrm{L}$ of each fraction were loaded on the surface of labeled filter paper disc, then incubated at $28{ }^{\circ} \mathrm{C}$ for $24 \mathrm{hrs}$ before measuring the zone of inhibition.

\section{Brine shrimp lethality assay}

Brine shrimp lethality bioassay as explained earlier [43] was adopted to study cytotoxic effect in different concentrations: 1000,100 and $10 \mu \mathrm{g} /$ $\mathrm{mL}$ of each fraction and standard drug $250 \mu \mathrm{L}$ of sea water was added to each well of 96 well plate. Afterwards, 10 brine shrimps (Artemia salina) were transferred to each well and volume of the wells was raised up to $300 \mu \mathrm{L}$ to attain desired concentration. These plates were incubated for 24 hours at room temperature. Then shrimps were taken from each well and survivors counted using magnifying glass. The lethal dose of crude fractions against brine shrimps was calculated using Finny software (1971).

\section{Antileishmanial Activity}

Antileishmanial activity was determined according to the protocol previously described [48]. Leishmania tropica KWH23 was kept warm at $24 \pm 1^{\circ} \mathrm{C}$ for 7 days in 199 medium having Fetal Bovine Serum (10\%). Antileishmanial activity was performed in 96 well plates using different dilutions of stock solution (10,000ppm) of the extract. Amphotericin B and distilled water were used as positive and negative controls, respectively. The 96 well plates were incubated at $24^{\circ} \mathrm{C}$ for $72 \mathrm{hrs}$. Afterwards, test culture (15 $\mu \mathrm{L})$ was transported to neubauer counting chamber to calculate live promastigotes under microscope.

\section{Results and discussion}

\section{Phytochemicals screening}

Measured level of TPC and TFC in HA1HA9 fractions are given in Table 1. TPC ranged from $9.24 \pm 0.001$ to $26.29 \pm 1.4 \mu \mathrm{gGAE} / \mathrm{mg}$ with decreasing order: HA $8>$ HA9 $>$ HA $1>$ HA3 $>$ HA $7>$ HA5 $>$ HA6 $>$ HA4 $>$ HA2. The highest concentration of TPC was determined for HA8, whereas HA2 depicted the lowest value. These values were comparable to the reported levels of TPC in the methanolic extract of other medicinal plants [21-51]. The HA1 fraction exhibited the highest TFC $(07.32 \pm 0.07 \mu \mathrm{gQE} / \mathrm{mg})$, whereas the lowest value was calculated for HA3 $(06.05 \pm 0.06 \mu \mathrm{gQE} / \mathrm{mg})$. The decreasing order of TFC different fractions was: HA $1>$ HA $8>$ HA7 $>$ HA $6>$ HA2 $>$ HA $5>$ HA $4>$ HA9 $>$ HA3.

\section{Antioxidant activity in A. vulgaris}

Comparison of DPPH free radical scavenging activity of HA1-HA9 fractions is given in 
Table 1. Total phenolics and flavonoids contents in different fractions of $\mathrm{A}$. vulgaris

\begin{tabular}{lcc}
\hline Fractions & TPC $(\mu \mathrm{g} \mathrm{GAE} / \mathrm{mg})$ & TPC $(\mu \mathrm{g} Q \mathrm{QE} / \mathrm{mg})$ \\
\hline HA-1 & $18.17 \pm 0.98$ & $07.32 \pm 0.07$ \\
\hline HA-2 & $09.24 \pm 0.01$ & $06.61 \pm 0.06$ \\
\hline HA-3 & $17.28 \pm 0.03$ & $06.05 \pm 0.06$ \\
\hline HA-4 & $09.37 \pm 0.03$ & $06.47 \pm 0.05$ \\
\hline HA-5 & $11.90 \pm 0.10$ & $06.47 \pm 0.01$ \\
\hline HA-6 & $11.36 \pm 0.10$ & $06.75 \pm 0.02$ \\
\hline HA-8 & $13.27 \pm 0.17$ & $07.04 \pm 0.01$ \\
\hline HA-9 & $26.29 \pm 1.40$ & $07.00 \pm 0.02$ \\
\hline
\end{tabular}

TPC. total phenolics content, TFC. total flavonoids contents, GAE. Gallic acid equivalent, QE. quercitin equivalent

Figure 1. In all fractions, the decreasing order of percentage DPPH scavenging activity was: HA $8>$ HA9 $>$ HA $>$ HA3 $>$ HA5 $>$ HA7 $>$ HA6 $>$ HA2 $>$ HA4. HA8 fraction depicted the highest percentage DPPH scavenging capacity $82.84 \pm 3.010 \%$, while HA4 showed the lowest scavenging $(04.71 \pm 0.001 \%)$. These findings were comparable with previous reports [28-49]. Mighri and coworkers in 2010 reported that $A$. herba-al$b a$ showed weak antioxidant potential [52]. In another study Artemisia abyssinica extracts also showed similar antioxidant potential [53].

Results showing ferric ion reducing power are given in Figure 2, showing decreasing or-

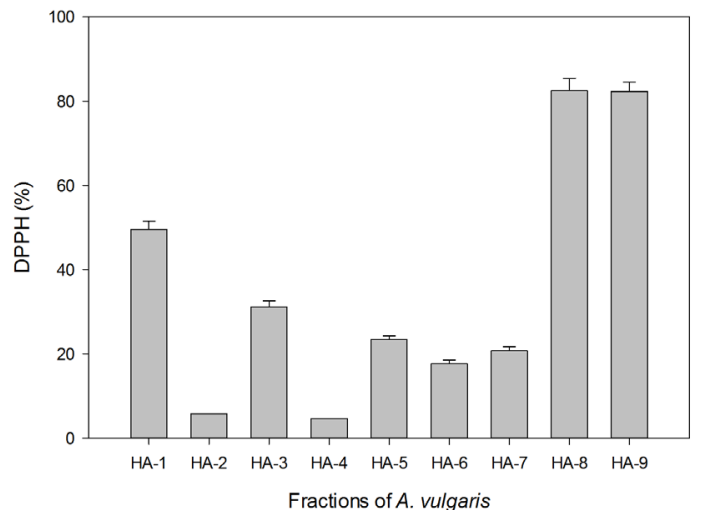

Fig. 1. Comparison of DPPH activity in HA1HA9 fractions of A. vulgaris der as: HA9 $>$ HA $8>$ HA $1>$ HA $3>$ HA $6>$ HA $7>$ HA5 $>$ HA4 $>$ HA2. The highest ferric ion reducing power was determined for HA-9 fraction $(176.9 \pm 8.45 \mathrm{mg} / \mathrm{mL})$, followed by HA-8 and HA-1 (173.16 \pm 9.54 and $135.5 \pm 4.21 \mathrm{mg} / \mathrm{mL}$, respectively), whereas the lowest value was noted for HA-2 $(35.31 \pm 1.9 \mathrm{mg} / \mathrm{mL})$. These results were similar to previous studies [21-50].

Total antioxidant capacity of HA1-HA9 fractions of $A$. vulgaris as given in Figure 3 depicted decreasing order as: HA $7>$ HA $3>$ HA $5>$ HA $8>$ HA9 $>$ HA $4>$ HA2 $>$ HA6 $>$ HA1. The HA 7 fraction showed the highest total antioxidant capacity, followed by HA-3 and HA-5 (96.25 \pm 3.29 ,

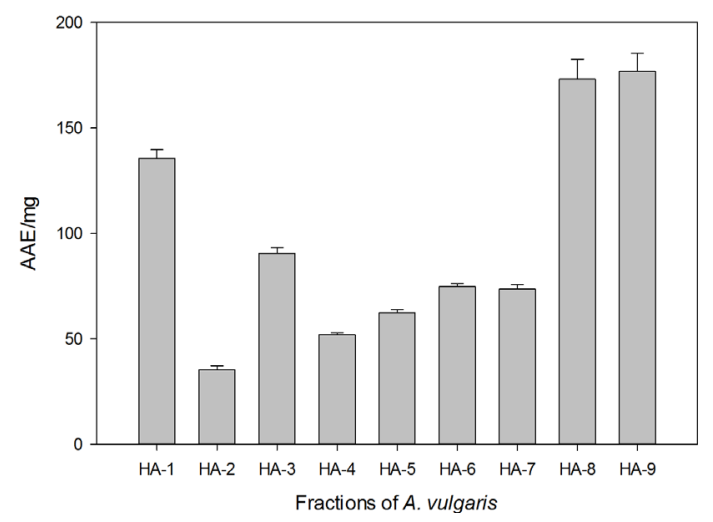

Fig. 2. Ferric ion reducing power in different fractions of $A$. vulgaris 


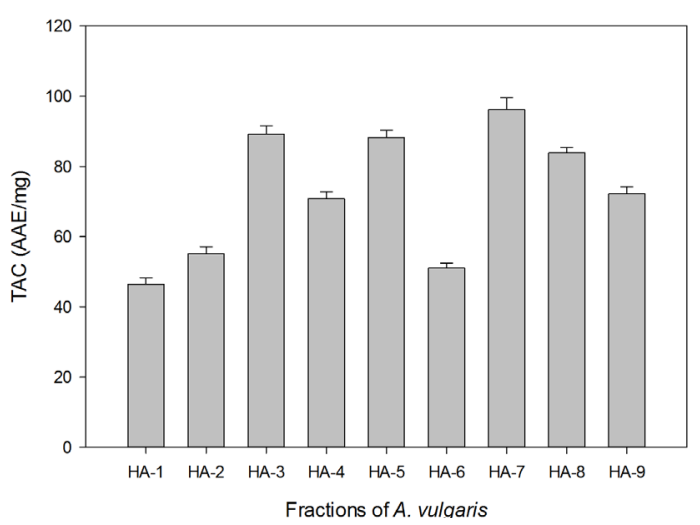

Fig. 3. Total antioxidant activity in different fractions of $\mathrm{A}$. vulgaris

$89.15 \pm 2.41$ and $88.26 \pm 2.13 \mathrm{AAE} / \mathrm{mg}$, respectively), whereas the lowest value was calculated for HA-1 (49.36 \pm 1.91$)$. Our results were comparable with previous reports [50].

\section{Antimicrobial potential}

Results showing antibacterial potential of HA1-HA9 fractions evaluated using disc diffusion methods against various pathogenic bacteria S. typhimurium, B. bronchiseptica and $M$. luteus are given in Table 2. Among bacterial strains $S$. typhimurium is a causative agent of salmonellosis in humans which is characterized by fever, acute intestinal inflammation, and diarrhea within $24 \mathrm{~h}$ after infection [54]. While $B$. bronchiseptica is a respiratory pathogen rarely causing infections but recently investigated as a causative agent of bacteremia and pancreatic abscess [55]. M. luteus was previously considered as non-pathogenic but recently it is considered an opportunistic pathogen, especially in immunocompromised patients. It is also responsible for nosocomial infections [56]. Keeping in view the pathogenicity of these bacterial strains, they were used in the current study.

All fractions didnot show any activity against $S$. typhimurium. This finding contradicted previous results, in which significant activity was shown by plant extracts against $S$. typhimurium [57]. In addition all fractions exhibited similar antibacterial potential against $B$. bronchiseptica and $M$. luteus. However, these results were in agreement with previous work [43-58]. In 2015, Addo-Mensah and coworkers reported significant antibacterial activities of extracts A. vulgaris against Staphylococcus aureus and Bacillus subtilis [59]. In another study it is reported that Artemisia dubia showed antibacterial potential [60].

Antifungal activity of HA1-HA9 factions was studied against fungal strains such as $\mathrm{Mu}$ cor species, A. niger and A. fumigatus (Table 2). Two fractions HA1 and HA2 showed activity against $A$.niger and Mucor spp., with values

Table 2 Antibacterial and antifungal activities (\% inhibition) ofHA1-HA9fractions

\begin{tabular}{lcccccc}
\hline \multirow{2}{*}{ Fractions } & \multicolumn{2}{c}{ Bacterial strains $(\mathrm{mm}$ zone of inhibition) } & \multicolumn{3}{c}{ Fungal strains $(\mathrm{mm}$ zone of inhibition) } \\
\cline { 2 - 7 } & S. typhimurium & B. bronchiseptica & M. luteus & A. niger & Mucor spp & A. fumigatus \\
\hline HA1 & --- & $6.000 \pm 00$ & $6.000 \pm 00$ & $11.00 \pm 0.11$ & $08.50 \pm 0.71$ & $07.50 \pm 0.71$ \\
\hline HA2 & --- & $6.000 \pm 00$ & $6.000 \pm 00$ & --- & $13.25 \pm 0.35$ & $08.00 \pm 10.41$ \\
\hline HA3 & --- & $6.000 \pm 00$ & $6.000 \pm 00$ & --- & $9.625 \pm 0.88$ & $06.50 \pm 0.71$ \\
\hline HA4 & --- & $6.000 \pm 00$ & $6.000 \pm 00$ & --- & $10.75 \pm 3.18$ & $02.50 \pm 3.54$ \\
\hline HA5 & --- & $6.000 \pm 00$ & $6.000 \pm 00$ & --- & $09.75 \pm 0.35$ & $02.50 \pm 3.54$ \\
\hline HA6 & --- & $6.000 \pm 00$ & $6.000 \pm 00$ & --- & $06.50 \pm 0.71$ & $03.00 \pm 4.24$ \\
\hline HA7 & --- & $6.000 \pm 00$ & $6.000 \pm 00$ & --- & $07.50 \pm 2.12$ & --- \\
\hline HA8 & --- & $6.000 \pm 00$ & $6.000 \pm 00$ & --- & $06.25 \pm 0.35$ & --- \\
\hline HA9 & --- & $6.000 \pm 00$ & $6.000 \pm 00$ & --- & $07.00 \pm 1.41$ & $07.00 \pm 1.41$ \\
\hline
\end{tabular}


of $11.00 \pm 0.11$ and $13.25 \pm 0.35 \mathrm{~mm}$ respectively. Likewise, in other medicinal plant species significant activity has been reported against this fungal species [28]. All other fractions also showed activity against Mucor spp., such as HA4, HA5 and HA3 (10.75 $\pm 3.18,09.75 \pm 0.35$ and $9.625 \pm 0.88 \mathrm{~mm}$ zone of inhibition, respectively). These results were in agreement with previous results [58].

\section{Brine shrimp lethality assay}

The cytotoxic effects of HA1-HA9 fractions determined by using brine shrimp lethality assay are given in Figure 4. As cytotoxicity is inversely proportional to $\mathrm{LD}_{50}$, therefore HA1 showed significant cytotoxic effect because it has the lowest $\mathrm{LD}_{50}$ value. However, $\mathrm{LD}_{50}$ value was the highest for HA7 fraction, which depicts the lowest cytotoxic effect. The decreasing order of cytotoxicity was: HA1 $>$ HA $8>$ HA4 \& HA5 $>$ HA $3>$ HA2 $>$ HA $6>$ HA9 $>$ HA 7 . These findings were in agreement with previous work [58].

\section{Antileishmanial activity}

Antileishmanial activity of HA1-HA9 fractions is given in Figure 5. In general, all fractions showed significant response except HA8 and HA9, as $0 \%$ survival of leishmania causing protozoa except fraction HA1 which showed

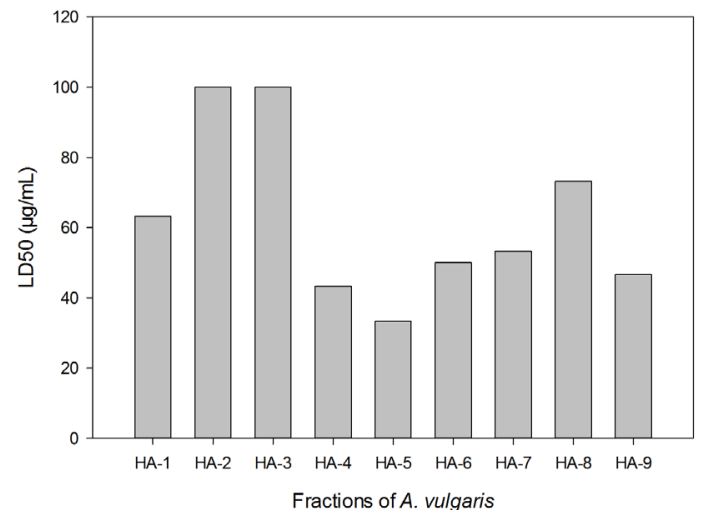

Fig. 4. Cytotoxic effects of A. vulgaris fractions
$19 \%$ survival was calculated. These results were in agreement with various reports [59].

\section{Conclusions}

The present study revealed that aerial parts of $A$. vulgaris possess significant potential as antioxidant, antimicrobial and antileishmanial agent. Their antileishmanial activity is very promising, which may cope with the modern scenario of discovering new resources of drugs.

\section{Conflicts of interest}

We have no conflict of interest.

\section{Authors' contribution}

$\mathrm{AH}$ and MA conducted research work and prepared initial drafts of MS, SAK and NF helped in data analysis, AMA and AM supervised the project, were involved in writing and data interpretation.

\section{References}

1. WHO (World Health Organization), Traditional and Alternative Medicine, Fact Sheet No 271. World Health Organization, Geneva 2002.

2. Donehower RC, Rowinsky EK. An overview of ex-

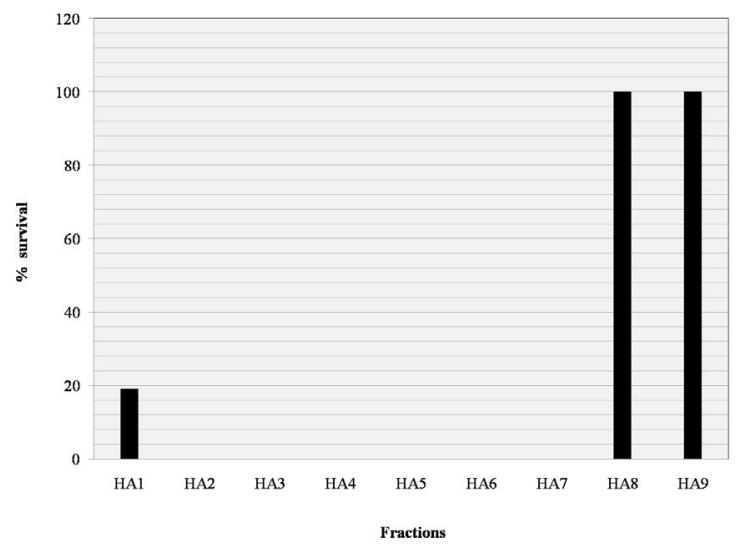

Fig. 5. Antileishmanial activity of HA1-HA9 fractions. 
perience with taxol (paclitaxel) in the USA. Canc Treatm Rev 1993; 19:63-8. DOI: 10.1016/03057372(93)90049-W

3. Huie CW. A review of modern sample-preparation techniques for the extraction and analysis of medicinal plants. Analyt Bioanalyt Chem 2002; 373(1-2): 23-30. DOI: $10.1007 / \mathrm{s} 00216-002-1265-3$

4. Nitta T, Arai T, Takamatsu H, Inatomi Y, Murata H, Iinuma $\mathrm{M}$, et al. Antibacterial Activity of Extracts Prepared from Tropical and Subtropical Plants on Methicillin-Resistant Staphylococcus aureus. J Health Sci 2002; 48(3):273-6. DOI: 10.1248/jhs.48.273

5. Ivanova D, Gerova D, Chervenkov T, Yankova T. Polyphenols and antioxidant capacity of Bulgarian medicinal plants. J Ethnopharmacol 2005; 96(1):145-50. DOI: 10.1016/j.jep.2004.08.033

6. Costa ES, Hiruma LCA, Lima EO, Sucupira GC, Bertolin AO, Lolis SF, et al. Antimicrobial activity of some medicinal plants of the Cerrado, Brazil. Phytotherap Res 2008; 22(5):705-07. DOI: 10.1002/ptr.2397

7. Nair R, Chanda S. Activity of some medicinal plants against certain pathogenic bacterial strains. Ind J Pharmacol 2006; 38(2):142-4. DOI: 10.4103/02537613.24625

8. Cowan MM. Plant products as antimicrobial agents. Clin Micro Rev 1999; 12(4);564-82.

9. Ahmad I, Mehmood Z, Mohammad F. Screening of some Indian medicinal plants for their antimicrobial properties. J Ethnopharmacol 1998; 62(2):183-93. DOI: 10.1016/S0378-8741(98)00055-5

10. Wright GD. Something old, something new: revisiting natural products in antibiotic drug discovery 1 . Canad $\mathrm{J}$ Micro 2014;6 0(3):147-4

11. Emori TG, Gaynes RP. An overview of nosocomial infections, including the role of the microbiology laboratory. Clin Micro Rev 1993; 6(4):428-42. DOI: 10.1128/ CMR.6.4.428

12. Pannuti CS, Grinbaum RS. An overview of nosocomial infection control in Brazil. Infec Control Hosp Epidem 1995; 16:170-4. DOI: 10.2307/30140967

13. Bartosz G. Reactive oxygen species: destroyers or messengers? Biochem Pharmacol 2009; 77(8):1303-15. DOI: 10.1016/j.bcp.2008.11.009

14. Lenaz G. Mitochondria and reactive oxygen species. Which role in physiology and pathology? In: Scatena R, Bottoni P, Giardina B editors. Advances in mitochondrial medicine vol 942. Advances in Experimental
Medicine and Biology, Springer Dordrecht, 2012; 93136. DOI: 10.1007/978-94-007-2869-1_5

15. Becker LB. New concepts in reactive oxygen species and cardiovascular reperfusion physiology. Cardiovascul Res 2004;61(3):461-70. DOI: 10.1016/j.cardiores.2003.10.025

16. Halliwell B. Oxidative stress and cancer: have we moved forward? Biochem J 2007; 401(1):1-11. DOI: 10.1042/BJ20061131

17. Harman D. The free radical theory of aging. Antioxidants and Redox Signaling 2003; 5(5):557-61. DOI: $10.1089 / 152308603770310202$

18. Jaeschke H. Reactive oxygen and mechanisms of inflammatory liver injury: present concepts. J Gastroenterol Hepatol 2011; 26(1):173-79. DOI: $10.1111 / \mathrm{j} .1440$ 1746.2010.06592.x

19. Reed TT. Lipid peroxidation and neurodegenerative disease. Free Rad Biol Med 2011;51(7):1302-19. DOI: 10.1016/j.freeradbiomed.2011.06.027

20. Venardos KM, Kaye DM. Myocardial ischemia-reperfusion injury, antioxidant enzyme systems, and selenium: a review. Curr Med Chem 2007; 14(14):1539-49. DOI: $10.2174 / 092986707780831078$

21. Bahorun T, Ramma AL, Amitabye, Alan C, Aruoma OI. Total phenol, flavonoid, proanthocyanidin and vitamin $\mathrm{C}$ levels and antioxidant activities of Mauritian vegetables. J Sci Food Agricul 2004; 84(12):1553-61. DOI: 10.1002/jsfa. 1820

22. Blois MS. Antioxidant determinations by the use of a stable free radical. Nature 1958; 181:1199-00. DOI: 10.1038/1811199a0

23. Halliwell B. Reactive oxygen species and the central nervous system Free Rad Brain 1992; 21-40.

24. Rao, YK, Geethangili M, Fang SH, Tzeng YM. Antioxidant and cytotoxic activities of naturally occurring phenolic and related compounds: a comparative study. Food Chem Toxicol 2007; 45(9):1770-6. DOI: 10.1016/j.fct.2007.03.012

25. Krings U, Berger RG. Antioxidant activity of some roasted foods. Food Chem 2001; 72(2):223-9. DOI: 10.1016/S0308-8146(00)00226-0

26. Sasidharan S, Chen Y, Saravanan D, Sundram KM, Latha LY. Extraction, isolation and characterization of bioactive compounds from plants' extracts. Afr J Tradit Complement Altern Med 2011; 8(1): 1-10

27. Osawa, T. Novel natural antioxidants for utilization in food and biological systems. In I. Uritani, V. V. Garcia, 
\& E. M. Mendoza Editors, Postharvest biochemistry of plant food-materials in the tropics Tokyo, Japan: Japan Scientific Societies Press pp. 241-51, 1994

28. Tabti L, Mohammed ElAD, Gaouar N, Samira B, Tabti, B. Antioxidant and Antifungal Activity of Extracts of the Aerial Parts of Thymus capitatus (L.) Hoffmanns Against Four Phytopathogenic Fungi of Citrus sinensis. Jundishapur J Nat Pharm Prod 2014; 9(1):49-4. DOI: 10.17795/jjnpp-13972

29. Prieto P, Pineda M, Aguilar M. Spectrophotometric quantitation of antioxidant capacity through the formation of a phosphomolybdenum complex: specific application to the determination of vitamin E. Analyt Biochem 1999; 269(2):337-41. DOI: 10.1006/ abio.1999.4019

30. Braga FG, Bouzada ML, Fabri RL, DeOMatos M, Moreira FO, Scio E, et al. Antileishmanial and antifungal activity of plants used in traditional medicine in Brazil. J Ethnopharmacol 2007; 111(2):396-02. DOI: 10.1016/j.jep.2006.12.006

31. Lu XL, Najafzadeh MJ, Dolatabadi S, Ran YP, Gerritisvanden AHG, Shen YN et al. Taxonomy and epidemiology of Mucor irregularis, agent of chronic cutaneous mucormycosis. Persoonia: Mol Phylog Evol Fung 2013; 30:48-56. DOI: 10.3767/003158513X665539

32. Schuster E, Dunn CN, Frisvad J, Van DP. On the safety of Aspergillus niger - a review. Appl Micro Biotechnol 2002; 59(4-5):426-35. DOI: 10.1007/s00253-0021032-6

33. Woolfrey BERTF, Moody JULIAA. Human infections associated with Bordetella bronchiseptica. Clin Micro Rev 1991; 4(3):243-55. DOI: 10.1128/CMR.4.3.243

34. Grimaldi G, Tesh RB. Leishmaniases of the New World: current concepts and implications for future research. Clin Micro Rev 1993; 6(3):230-50. DOI: 10.1128/CMR.6.3.230

35. Singh S, Sivakumar R. Challenges and new discoveries in the treatment of leishmaniasis. J Infec Chemothr 2004; 10(6):307-15. DOI: 10.1007/s10156-004-0348-9

36. Sundar S, Rai M. Laboratory diagnosis of visceral leishmaniasis. Clin Diagn Lab Immunol 2002; 9(5):951-8. DOI: 10.1128/CDLI.9.5.951-958.2002

37. Beukelman CJ, Vanden WE, Henriette C, Van UQ, Kroes BH, Vanden BJ. Discovery of new anti-inflammatory drugs from plant origin. Annals Gastroenterol 2002; 15(4):320-3.

38. Chohan ZH, Shaikh AU, Rauf A, Supuran CT. Anti- bacterial, antifungal and cytotoxic properties of novel $\mathrm{N}$-substituted sulfonamides from 4-hydroxycoumarin. J Enz Inhibit Med Chem 2006; 21(6):741-8. DOI: 10.1080/14756360600810340

39. Khan A, Gilani AH. Antispasmodic and bronchodilator activities of Artemisia vulgaris are mediated through dual blockade of muscarinic receptors and calcium influx. J Ethnopharmacol 2009; 126(3):480-6. DOI: 10.1016/j.jep.2009.09.010

40. Pires JM, Mendes FR, Negri G, Almeida DJM, Carlini EA. Antinociceptive peripheral effect of Achillea millefolium L. and Artemisia vulgaris L.: both plants known popularly by brand names of analgesic drugs. Phytother Res 2009; 23(2): 212-9. DOI: 10.1002/ptr.2589

41. Gilani AH, Yaeesh S, Jamal Q, Ghayur MN. Hepatoprotective activity of aqueous-methanol extract of Artemisia vulgaris. Phytother Res 2005; 19(2):170-2. DOI: $10.1002 /$ ptr.1632

42. Clarke G, Ting KN, Wiart C, Fry J. High correlation of 2, 2-diphenyl-1-picrylhydrazyl (DPPH) radical scavenging, ferric reducing activity potential and total phenolics content indicates redundancy in use of all three assays to screen for antioxidant activity of extracts of plants from the Malaysian rainforest. Antioxidants 2013;2(1):1-10. DOI: 10.3390/antiox2010001

43. Haq I, Ullah N, Bibi G, Kanwal S, Ahmad MS, Mirza B. Antioxidant and cytotoxic activities and phytochemical analysis of Euphorbia wallichii root extract and its fractions. Iran J Pharm Res 2012;11(1):241-9.

44. Lee SE, Hwang HJ, Ha JS, Jeong HS, Kim JH. Screening of medicinal plant extracts for antioxidant activity. Life Sci 2003; 73(2):167-9. DOI: 10.1016/S00243205(03)00259-5

45. Ullah N, Haq I, Safdar N, Mirza B. Physiological and biochemical mechanisms of allelopathy mediated by the allelochemical extracts of Phytolacca latbenia (Moq.) H. Walter. Toxicol Ind Health 2013; 31(10): 931-7. DOI: $10.1177 / 0748233713483205$

46. Zaidi MA, Crow SA. Biologically active traditional medicinal herbs from Balochistan, Pakistan. J Ethnopharmacol 2005; 96(1):331-4. DOI: 10.1016/j. jep.2004.07.023

47. Manavathu EK, Ramesh MS, Baskaran I, Ganesan LT, Chandrasekar PH. A comparative study of the post-antifungal effect (PAFE) of amphotericin B, triazoles and echinocandins on Aspergillus fumigatus and Candida albicans. J Antimicrob Chemother 2004; 53(2):386-89. 
DOI: $10.1093 / \mathrm{jac} / \mathrm{dkh} 066$

48. Ma G, Khan SI, Jacob MR, Tekwani BL, Li Z, Pasco DS, et al. Antimicrobial and antileishmanial activities of hypocrellins A and B. Antimicrob Agents Chemother 2004; 48(11):4450-52. DOI: 10.1128/AAC.48.11.44504452.2004

49. Ali N, Shah I, Shah SWA, Ahmed G, Shoaib M, Junaid $\mathrm{M}$, et al. Antioxidant and relaxant activity of fractions of crude methanol extract and essential oil of Artemisiamacrocephala jacquem. BMC Complement Alternat Med 2013; 13(1):96. DOI: 10.1186/1472-6882-13-96

50. Medini F, Fellah H, Ksouri R, Abdelly C. Total phenolic, flavonoid and tannin contents and antioxidant and antimicrobial activities of organic extracts of shoots of the plant Limonium delicatulum. J Taib Univ Sci 2014; 8(3):216-24. DOI: 10.1016/j.jtusci.2014.01.003

51. Ahameethunisa AR, Hopper W. Antibacterial activity of Artemisia nilagirica leaf extracts against clinical and phytopathogenic bacteria. BMC complement Alternat Med 2010; 10(1):6. DOI: 10.1186/1472-6882-10-6

52. Mighri H, Ahmed HH, Najjaa AK, Neffati M. Antimicrobial and antioxidant activities of Artemisia herba-alba essential oil cultivated in Tunisian arid zone. Comptes Rendus Chimie 2010; 13(3): 380-6 DOI: 10.1016/j. crci.2009.09.008

53. Youssef MM, Mahmoud AA, Al-Faiyz YSS. Antimicrobial and Antioxidant Activities of Artemisia abyssinica
Extracts and DNA Degradation Effects. Asian J. Biochem 2015;10(1):31-41. DOI: 10.3923/ajb.2015.31.41

54. Matic NA, Bunce PE. Isolation of Bordetella bronchiseptica from blood and a pancreatic abscess. J. Clin. Microbiol 2015; 53:1778-80. DOI: 10.1128/ JCM.00175-15

55. Uso J, Gill M, Gomila B, Tirado MD. Endocarditis due to Micrococcus luteus. Microbiol Clin 2003; 21:116-7.

56. Al Bayati FA. Synergistic antibacterial activity between Thymus vulgaris and Pimpinella anisum essential oils and methanol extracts. J Ethnopharmacol 2008;116(3):403-6. DOI: 10.1016/j.jep.2007.12.003

57. Mannan A, Inayatullah S, Akhtar MZ, Qayyum M, Mirza B. Biological evaluation of wild thyme (Thymus serpyllum). Pharm Biol 2009;47(7):628-33. DOI: 10.1080/13880200902915622

58. Rocha LG, Almeida JRGS, Macedo RO, Barbosa FJM. A review of natural products with antileishmanial activity. Phytomed 2005;12(6):514-5. DOI: 10.1016/j. phymed.2003.10.006

59. Addo-Mensah A, Garcia G, Maldonado IA, Anaya E, Cadena, G Lee LG. Evaluation of Antibacterial Activity of Artemisia vulgaris Extracts. Research J. Medic Plants 2015;9:234-40. DOI: 10.3923/rjmp.2015.234.240

60. Ihsan-ul-Haq A, Ahmed I, Hussain I, Jamil M, Mirza B. Antibacterial activity and brine shrimp toxicity of Artemisia dubia extract. Pakistan J. Bot 2012;44(4):1487-90. 